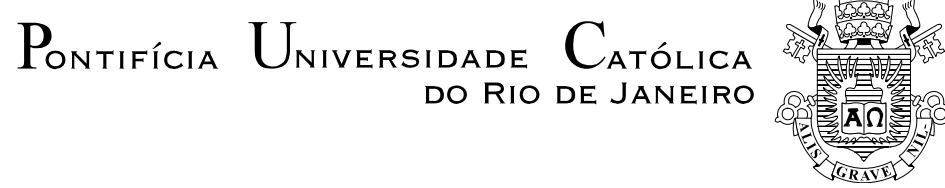

Geisa Rodrigues Leite da Silva

\title{
AS MÚLTIPLAS FACES DE MADAME SATÃ \\ Estéticas e políticas do corpo
}

Tese de Doutorado

Tese apresentada ao Programa de Pós-graduação em Letras da PUC-Rio como requisito parcial para obtenção do título de Doutor em Letras.

Orientadora: Ana Paula Veiga Kiffer

Rio de Janeiro

Fevereiro de 2011 


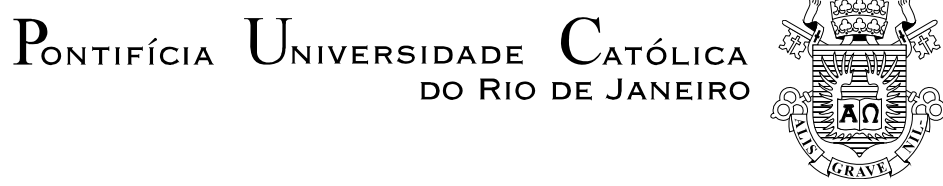

Geisa Rodrigues Leite da Silva

As múltiplas faces de Madame Satã:
estéticas e políticas do corpo

Tese apresentada como requisito parcial para obtenção do grau de Doutor pelo Programa de Pós-Graduação em Letras do Departamento de Letras do Centro de Teologia e Ciências Humanas da PUC-Rio. Aprovada pela Comissão Examinadora abaixo assinada.

Profa. Ana Paula Veiga Kiffer Orientadora

Departamento de Letras - PUC-Rio

Profa. Marília Rothier Cardoso

Departamento de Letras - PUC-Rio

Prof. Júlio Cesar Valladão Diniz Departamento de Letras - PUC-Rio

Profa. Luciana Leila Fontes Vieira UFPE

Profa. Nizia Maria Souza Villaça UFRJ

Profa. Denise Berruezo Portinari Coordenadora Setorial do Centro de Teologia

e Ciências Humanas - PUC-Rio

Rio de Janeiro, 25 de Fevereiro de 2011. 
Todos os direitos reservados. É proibida a reprodução total ou parcial do trabalho sem autorização da universidade, da autora e do orientador.

\section{Geisa Rodrigues Leite da Silva}

Graduou-se em Comunicação Social (Publicidade e propaganda) pela Universidade Federal do Espírito Santo, em 1994. Defendeu dissertação de Mestrado no programa de Pós-graduação em Comunicação e Imagem da Universidade Federal Fluminense em 2002. Ingressou no Programa de Pós-graduação em Letras da PUC-Rio em 2007. É professora do Curso de Comunicação Social da Universidade Federal Fluminense desde 2003. Apresentou e publicou diversos trabalhos nas áreas de Comunicação, Cinema e Letras.

Ficha Catalográfica

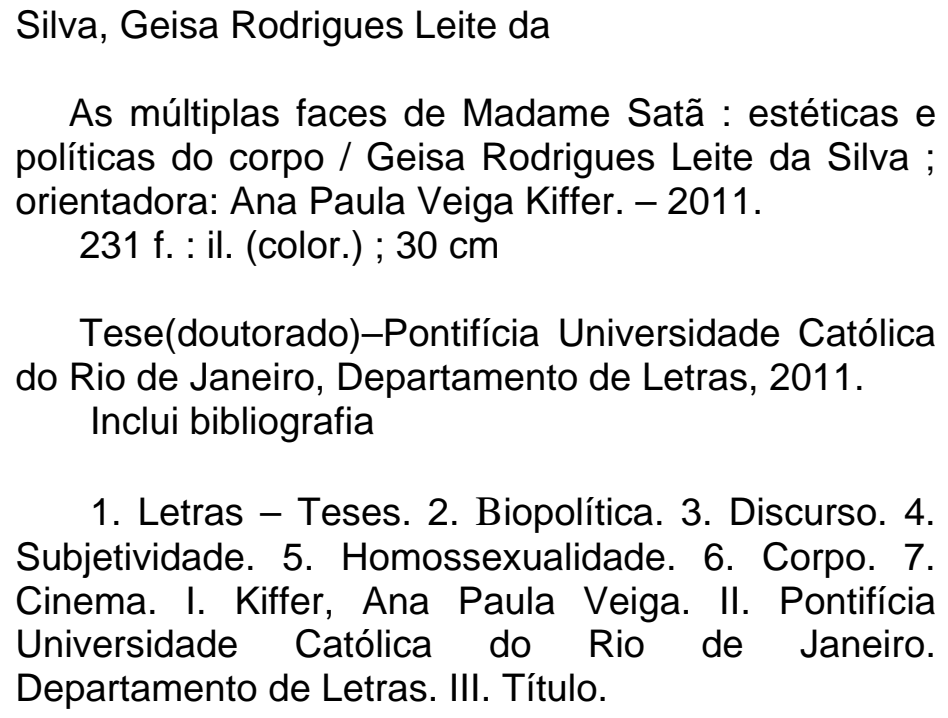
políticas do corpo / Geisa Rodrigues Leite da Silva ; orientadora: Ana Paula Veiga Kiffer. - 2011. 231 f. : il. (color.) ; $30 \mathrm{~cm}$

Tese(doutorado)-Pontifícia Universidade Católica do Rio de Janeiro, Departamento de Letras, 2011. Inclui bibliografia

1. Letras - Teses. 2. Biopolítica. 3. Discurso. 4. Subjetividade. 5. Homossexualidade. 6. Corpo. 7. Cinema. I. Kiffer, Ana Paula Veiga. II. Pontifícia Universidade Católica do Rio de Janeiro. Departamento de Letras. III. Título. 
À minha mãe, a outra Geisa, pelo amor incondicional

À Morena, que desde a barriga acompanhou este percurso, e aprendeu a andar e a falar em meio a livros e papéis. Depois dela, o que era complicado ficou simples e o simples cada vez mais completo.

Ao Café, pelo afeto, pelo amor, e por compartilhar seu tempo e seu corpo comigo. 


\section{Agradecimentos}

À minha orientadora, Ana Paula Veiga Kiffer, pela dedicação nesta parceria e pelo olhar apurado e inspirador.

Aos professores Marília Rothier Cardoso, Karl Erick Schollhammer e Julio César Valladão Diniz, pelas valiosas contribuições para este percurso.

À Paula Sibilia, pela participação na qualificação, pela amizade e pelo empréstimo de diversas referências bibliográficas.

A todos os amigos que me ajudaram com idéias, livros, tempo, cervejas, cafés, colinho amigo e longos telefonemas desesperados, Alceste Pinheiro, Alessandra Gomes, Alexandre Ferreira de Mendonça, Kleber Mendonça, Mariana Baltar, Patrícia Correia, Rodrigo Labriola e Tadeu Capistrano. E aos que, pelo cansaço de final de tese, não fizeram parte desta lista, apesar de merecerem.

Aos colegas do departamento de Comunicação da UFF, que, além de companheiros, foram extremamente compreensivos concedendo-me um período de afastamento das minhas atividades, essencial para conciliar tese e maternidade.

À Puc-Rio, pela bolsa de isenção que permitiu a realização desta pesquisa.

Aos funcionários do Departamento de Letras, sempre prontos a nos atenderem com carinho e presteza. 


\section{Resumo}

Silva, Geisa Rodrigues Leite da; Kiffer, Ana Paula Veiga. As múltiplas faces de Madame Satã : estéticas e políticas do corpo. Rio de Janeiro, 2011. 231p. Tese de Doutorado - Departamento de Letras, Pontifícia Universidade Católica do Rio de Janeiro.

Madame Satã é sem dúvida um dos representantes mais ilustres da malandragem da Lapa boêmia da primeira metade do século XX. Mas o personagem reúne, ainda, traços que o inserem em outras categorias, tais como, negro, homossexual e marginal. Esta tese busca desvendar um complexo processo em que se imbricam a apropriação (e resignificação) simbólica do malandro e a aplicação de estratégias biopolíticas sobre os corpos "fora da norma”. Os desdobramentos identitários de Madame Satã sugerem também uma potência política a ser explorada. Ao longo dos anos, as interpretações do personagem vão das mais conservadoras às mais transgressoras, deixando entrever, além dos diferentes contextos em que se inserem, os distintos projetos estéticos e políticos delineados. O objetivo principal deste trabalho é analisar o percurso de Madame Satã e promover uma reflexão sobre o poder de instrumentalização do corpo, tendo como horizonte a produção de subjetividades contemporâneas. Além do período em que o personagem se insere, dois momentos específicos são analisados: a década de setenta, quando retornará à cena midiática via uma entrevista concedida ao jornal O Pasquim e publicará uma autobiografia, e o início do século XXI, a partir do lançamento do filme Madame Satã, de Karim Aïnouz.

\section{Palavras-chave}

Biopolítica ; discurso; subjetividade; homossexualidade; corpo; cinema. 


\section{Abstract}

Silva, Geisa Rodrigues Leite da; Kiffer, Ana Paula Veiga(Advisor). The many faces of Madame Satã: aesthetics and politics of the body. Rio de Janeiro, 2011. 231p. Doctoral Thesis - Departamento de Letras, Pontifícia Universidade Católica do Rio de Janeiro.

Madame Satã is no doubt one of the most famous representative of the "malandragem" from the first half of XX century. But the character includes, indeed, features that insert him into other categories as, black, homosexual and delinquent. This study aims to reveal a complex process that imbricates symbolic appropriation (and re-signification) of the "malandro", and the applying of biopolitical strategies over the "out of normative” bodies. The identity unfoldings of Madame Satã suggests also a political potency to be explored. Over the years, the character interpretations go from the most conservative to the most transgressors, breaking out, besides the different contexts to which they belong, the distinct aesthetical and political projects delineated. The main purpose of this work is to analyse Madame Satã's course and to promote a reflection about the power of body's instrumentalization, taking the contemporary subjectivities production as the horizon for reflection. As well as his acting age, two specific moments are analyzed: The seventies, when he was put back on the media scene and published an autobiography, and the XXI century, after the release of the film Madame Satã (2002), by Karim Aïnouz.

\section{Keywords}

Biopolitics; discourse; subjectivity; homosexuality; body; cinema. 


\section{Sumário}

1. Introdução 10

2. A rainha da ralé na cidade maravilhosa 18

2.1. Um corpo fora da norma ou anormal? 23

2.2. Nas tramas da República Nova 33

3. Madame Satã e a justa: nas tramas do discurso 53

3.1. Com a palavra a autoridade 56

3.2. O poder da sexualidade?. 68

3.3. Alguma coisa está fora da ordem 78

4. Anos 70: eis o malandro na praça outra vez 92

4.1. 1971 , o retorno 94

4.2. Memórias de Madame Satã: palavra de malandro 110

4.3. 1976, a despedida 139

5. Madame Satã e o século XXI 151

5.1. Novos olhares sobre Madame Satã 159

5.2. Madame Satã, o filme 174

5.2.1. O corpo de Satã em cena 176

5.2.2. Madame Satã enquadrado 185

$\begin{array}{ll}\text { 5.2.3. A voz do corpo negro } & 197\end{array}$

5.2.4. O crime, a prisão e a fuga 204

6. Considerações finais 211 
Anexo A - Primeira página, ed. nº 95, 1971, O Pasquim 228

Anexo B - Capa do livro Memórias de Madame Satã 229

Anexo C - Contracapa do livro Memórias de Madame Satã 230

Anexo D - Logomarca do selo Navalha records e foto de grafite 231 